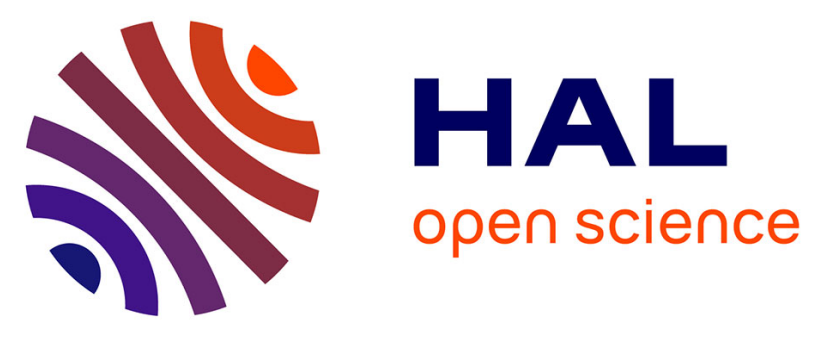

\title{
DISCO: a low-energy multipurpose beamline at synchrotron SOLEIL
}

\author{
Alexandre Giuliani, Frédéric Jamme, Valérie Rouam, Frank Frank Wien, \\ Jean-Luc Giorgetta, Bruno Lagarde, Oleg Chubar, Stéphane Bac, Isabelle \\ Yao, Solène Rey, et al.
}

\section{To cite this version:}

Alexandre Giuliani, Frédéric Jamme, Valérie Rouam, Frank Frank Wien, Jean-Luc Giorgetta, et al.. DISCO: a low-energy multipurpose beamline at synchrotron SOLEIL. Journal of Synchrotron Radiation, 2009, 16 (Pt 6), pp.835 - 841. 10.1107/S0909049509034049 . hal-01479318

\section{HAL Id: hal-01479318 https://hal.science/hal-01479318}

Submitted on 28 Feb 2017

HAL is a multi-disciplinary open access archive for the deposit and dissemination of scientific research documents, whether they are published or not. The documents may come from teaching and research institutions in France or abroad, or from public or private research centers.
L'archive ouverte pluridisciplinaire $\mathbf{H A L}$, est destinée au dépôt et à la diffusion de documents scientifiques de niveau recherche, publiés ou non, émanant des établissements d'enseignement et de recherche français ou étrangers, des laboratoires publics ou privés. 
Journal of

Synchrotron

Radiation

ISSN 0909-0495

Editors: G. Ice, Å. Kvick and T. Ohta

\title{
DISCO: a low-energy multipurpose beamline at synchrotron SOLEIL
}

\author{
Alexandre Giuliani, Frédéric Jamme, Valérie Rouam, Frank Wien, Jean-Luc \\ Giorgetta, Bruno Lagarde, Oleg Chubar, Stéphane Bac, Isabelle Yao, \\ Solène Rey, Christian Herbeaux, Jean-Louis Marlats, Daniel Zerbib, \\ François Polack and Matthieu Réfrégiers
}

J. Synchrotron Rad. (2009). 16, 835-841

Copyright (C) International Union of Crystallography

Author(s) of this paper may load this reprint on their own web site or institutional repository provided that this cover page is retained. Republication of this article or its storage in electronic databases other than as specified above is not permitted without prior permission in writing from the IUCr.

For further information see http://journals.iucr.org/services/authorrights.html

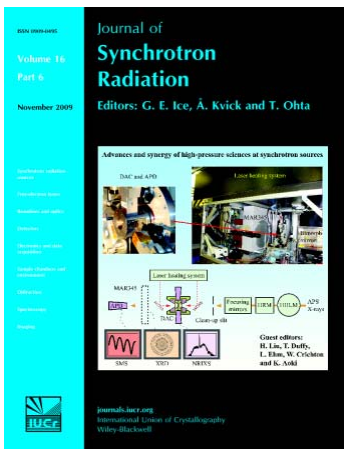

Synchrotron radiation research is rapidly expanding with many new sources of radiation being created globally. Synchrotron radiation plays a leading role in pure science and in emerging technologies. The Journal of Synchrotron Radiation provides comprehensive coverage of the entire field of synchrotron radiation research including instrumentation, theory, computing and scientific applications in areas such as biology, nanoscience and materials science. Rapid publication ensures an up-to-date information resource for scientists and engineers in the field.

Crystallography Journals Online is available from journals.iucr.org 
Journal of

Synchrotron

Radiation

ISSN 0909-0495

Received 20 March 2009

Accepted 25 August 2009

\section{DISCO: a low-energy multipurpose beamline at synchrotron SOLEIL}

\author{
Alexandre Giuliani, ${ }^{\mathrm{a}, \mathrm{b}} \neq$ Frédéric Jamme, ${ }^{\mathrm{a}, \mathrm{b}} \neq$ Valérie Rouam, ${ }^{\mathrm{a}} \neq$ Frank Wien, ${ }^{\mathrm{a}} \neq$ \\ Jean-Luc Giorgetta, ${ }^{a}$ Bruno Lagarde, ${ }^{a}$ Oleg Chubar, ${ }^{a}$ Stéphane Bac, ${ }^{\text {a Isabelle Yao, }}$ \\ Solène Rey, ${ }^{a}$ Christian Herbeaux, ${ }^{a}$ Jean-Louis Marlats, ${ }^{a}$ Daniel Zerbib, ${ }^{a}$ \\ François Polack ${ }^{a}$ and Matthieu Réfrégiers ${ }^{\mathrm{a} *}$ \\ asynchrotron SOLEIL, L'Orme des Merisiers, 91192 Gif sur Yvette Cedex, France, and ${ }^{\mathbf{b}}$ Cepia, \\ Institut National de la Recherche Agronomique (INRA), BP 71627, 44316 Nantes Cedex 3, France. \\ E-mail: matthieu.refregiers@synchrotron-soleil.fr
}

\begin{abstract}
DISCO, a novel low-energy beamline covering the spectrum range from the VUV to the visible, has received its first photons at the French synchrotron SOLEIL. In this article the DISCO design and concept of three experimental stations serving research communities in biology and chemistry are described. Emphasis has been put on high flux generation and preservation of polarization at variable energy resolutions. The three experiments include a completely new approach for microscopy and atmospheric pressure experiments as well as a 'classical' synchrotron radiation circular dichroism station. Preliminary tests of the optical design and technical concept have been made. Theoretical predictions of the beam have been compared with the first images produced by the first photons originating from the large-aperture bending-magnet source. Results are also reported concerning the cold finger used to absorb hard X-ray radiation in the central part of the synchrotron beam and to avoid heavy thermal load on the following optics. Wavelength selection using monochromators with different gratings for each experimental set-up as well as beam propagation and conditioning throughout the optical system are detailed. First photons comply very well with the theoretical calculations.
\end{abstract}

(C) 2009 International Union of Crystallography Printed in Singapore - all rights reserved

\section{Introduction}

The range from vacuum ultraviolet (VUV) to visible on thirdgeneration synchrotrons is somewhat exotic considering that only a few beamlines working in this domain are under the process of design or already designed. Most of them focus on circular dichroism and spectroscopy between 3 and $7 \mathrm{eV}$ (Sutherland et al., 1980; Gekko et al., 2001; Tao et al., 2001; Clarke \& Jones, 2004; Matsuo et al., 2005; Hoffmann et al., 2007).

In the case of the SOLEIL synchrotron radiation facility, a $2.75 \mathrm{GeV}$ storage ring, the DISCO (dichroism, imaging and spectroscopy for biology) beamline will cover the $1-20 \mathrm{eV}$ photon energy range. This paper presents the general concept, implementation and how the issues encountered during the construction of DISCO beamline were solved.

The DISCO beamline possesses three end-stations with different requirements (Figs. 1 and 2). The synchrotron radiation circular dichroism (SRCD) experiment covers the

$¥$ These authors have contributed equally to the publication of this article. wavelength range 600-130 nm (2-9.5 eV) (Miron et al., 2005), with maximized conservation of natural polarization from the bending magnet. The spot size at the experimental chamber allows full irradiation of the absorption cell $(3 \mathrm{~mm}$ in diameter). SRCD shares beam time with a branch line referred to as the atmospheric pressure experiment (APEX). APEX delivers photons windowless in the 300-60 $\mathrm{nm}$ range (4.1-20 eV) at atmospheric pressure. A differential pumping stage accommodates for pressure differences between the sample and the beamline. The horizontal focal point position has been chosen in order to have the smallest spot size at the entrance port of the differential pumping. The third endstation, which works in parallel with the two other branch lines, is a microscope using $1000-180 \mathrm{~nm}(1.2-6.9 \mathrm{eV})$ fully tunable excitation with special emphasis on the use of the synchrotron radiation time structure for lifetime by phase modulation measurements.

All optical parameters were optimized using SOLEMIO, an in-house software that combines ray-tracing calculations and optimization iterations. 


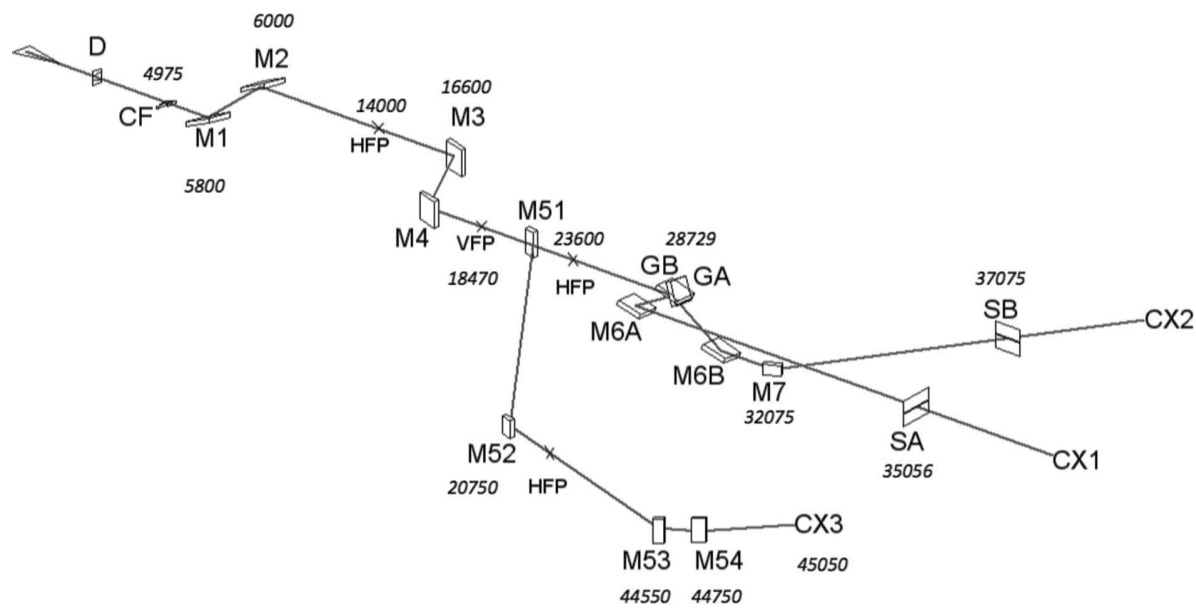

Figure 1

Optical layout of the DISCO beamline. D, diaphragm; CF, cold finger; $\mathrm{M} x$, mirrors (for mirror number refer to Table 1); Gx , gratings (for grating number refer to Table 1); HFP, horizontal focal point; VFP, vertical focal point; CX1, SRCD end-station; CX2, APEX end-station; CX3, microscopy end-station. Distances from the source point are indicated in $\mathrm{mm}$ for some elements. gies are concentrated in the vertical central part of the beam. Therefore, a symmetric extraction of the upper and lower parts implies the exclusion of the central part (Fig. 3). Two possibilities are then opened: either a slotted mirror, as used by the infrared beamlines (Dumas et al., 2006), or a central absorber placed upstream of the first mirror. A slotted mirror implies a very good surface polishing of the slit edges which is not trivial in the proposed energy range. On the other hand, a central absorber may be centred relatively easily on the beam to absorb the energetic photons. It was decided to position a cold finger of thickness $7.5 \mathrm{~mm}$ to intercept a vertical angle of $1.5 \mathrm{mrad}$ in the middle of the beam at a distance of $825 \mathrm{~mm}$ of the first M1

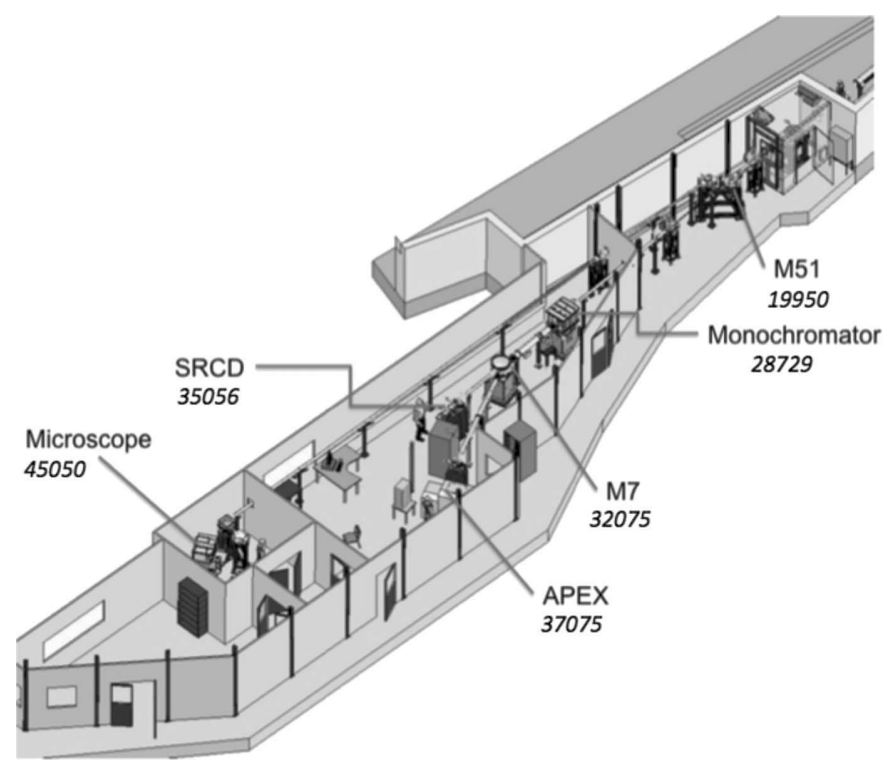

Figure 2

Layout of the DISCO beamline in the experimental hall at SOLEIL. Distances from the source point are indicated in $\mathrm{mm}$ for some elements.

\section{Front-end requirements and constraints}

\subsection{General comments}

The beam, extracted from a bending-magnet, D4.1 (1.71 T, bending angle $11.25^{\circ}$ ), has a $50 \mathrm{mrad} \times 10 \mathrm{mrad}$ divergence. It is defined in size by the aperture of a crotch absorber located at $1.5 \mathrm{~m}$ from the bending-magnet exit. Vertically the $5 \mathrm{mrad}$ above and under the central emittance allow for the collection of all energies down to $1.2 \mathrm{eV}$, with a symmetric distribution from the highest to the lowest energies (Fig. 3). The large horizontal extraction of $50 \mathrm{mrad}$ provides the necessary flux.

\subsection{Front-end energy selection}

As a low-energy beamline, the first point to resolve is the non-standard extraction of the beam. Most of the high ener- mirror (Fig. 1). With this design, the cold finger absorbs the entire $3 \mathrm{~kW}$ for a $500 \mathrm{~mA}$ storage-ring current. This heat load is dissipated by two water circuits with an inlet temperature of 294 K. At $300 \mathrm{~mA}$ storage-ring current, the outlet temperature measured was $300 \mathrm{~K}$. The cold finger shape was designed to minimize vertical and horizontal deformation under thermal stress. Moreover, it is made of glidcop owing to the better thermal performances of this material with respect to copper (Troxell, 1989).

At the back of the cold finger a $0.5 \mathrm{~mm}$ blade prevents the propagation of diffracted X-rays originating from the front edge of the cold finger further to the first mirror. Hence, the

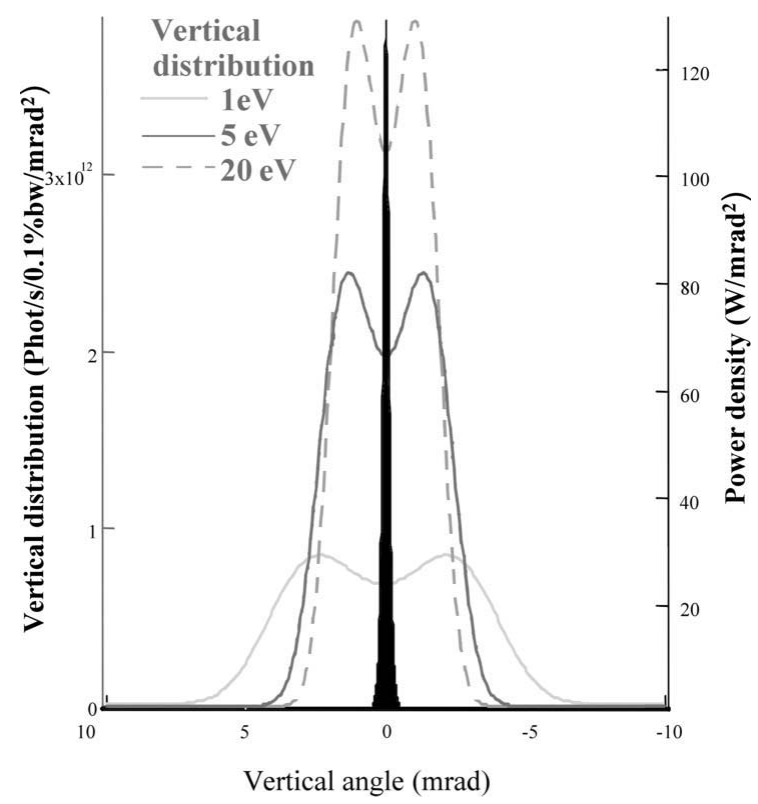

Figure 3

Vertical distribution profiles of the photon fluxes emitted by a dipole for a $50 \mathrm{mrad}(\mathrm{V}) \times 10 \mathrm{mrad}(\mathrm{H})$ aperture at $1 \mathrm{eV}$ (light gray), $5 \mathrm{eV}$ (dark gray) and $20 \mathrm{eV}$ (dotted line). $99.15 \%$ of the total power density (in black, right-hand axis) is concentrated in the central mrad. 
Table 1

$R$ : tangential radius. $r$ : sagittal radius. vls: variable line spacing.

\begin{tabular}{|c|c|c|c|c|c|}
\hline $\begin{array}{l}\text { Optical } \\
\text { element }\end{array}$ & Optical property & $\begin{array}{l}\text { Distance from } \\
\text { source }(\mathrm{mm})\end{array}$ & $\begin{array}{l}\text { Grazing } \\
\text { incidence }\end{array}$ & Material & Radius of curvature \\
\hline M1 & Cylindrical convex & 5800 & $22.5^{\circ}$ & $\mathrm{Si}$ & $r=-75 \mathrm{~m}$ \\
\hline M2 & Toroidal & 6000 & $22.5^{\circ}$ & $\mathrm{Si}$ & $R=21.04 \mathrm{~m}, r=2.56 \mathrm{~m}$ \\
\hline M3 & Elliptic cylindrical & 16600 & $22.5^{\circ}$ & $\mathrm{Si}$ & $R=9.93 \mathrm{~m}$ \\
\hline M4 & Plane & 16800 & $22.5^{\circ}$ & $\mathrm{Si}$ & - \\
\hline M51 & Sphere convex & 19950 & $22.5^{\circ}$ & $\mathrm{Si}$ & $R=-35 \mathrm{~m}$ \\
\hline M52 & Cylindrical & 20750 & $20.65^{\circ}$ & $\mathrm{AlMgF}_{2}$ & $r=2 \mathrm{~m}$ \\
\hline M53 & Toroidal & 44500 & 22.5 & $\mathrm{AlMgF}_{2}$ & $R=4.75 \mathrm{~m}, r=0.714 \mathrm{~m}$ \\
\hline M54 & Toroidal & 44750 & $22.5^{\circ}$ & $\mathrm{AlMgF}_{2}$ & $R=7.80 \mathrm{~m}, r=1.12 \mathrm{~m}$ \\
\hline M6A & Toroidal & 28556 & $75^{\circ}$ & $\mathrm{Ru}$ & $R=7.87 \mathrm{~m}, r=5.56 \mathrm{~m}$ \\
\hline M6B & Spherical & 29075 & $15^{\circ}$ & $\mathrm{Si}$ & $R=35.4 \mathrm{~m}$ \\
\hline M7 & Cylindrical & 32075 & $11^{\circ}$ & $\mathrm{Si}$ & $R=37.85 \mathrm{~m}$ \\
\hline GA & Plane, 400 lines $\mathrm{mm}^{-1}$ (vls) & 28729 & $75^{\circ}$ & $\mathrm{Ru}$ & - \\
\hline GB & Plane, 250 lines $\mathrm{mm}^{-1}$ (vls) & 28729 & $15^{\circ}$ & $\mathrm{Si}$ & - \\
\hline
\end{tabular}

Optical parameters of the mirrors.

favour of photoelectrons. Comparisons between desorption level and photoelectron emission level show behaviour independent of the incident photons' energetic spectrum (Hori et al., 1993). It clearly demonstrates the correlation between desorption and photoelectrons emission. The photodesorption occurs from surfaces close to the illuminated part of the chambers, which are exposed to the emitted photoelectrons. Hence, it has been shown that applying a negative electric field close to those illuminated areas reduces desorption (Kobari et al., 1990).

In order to reduce the risk of residual power reaching the first mirror M1 (size $190 \times$ $260 \mathrm{~mm}$ ) has been calculated to amount to less than $5 \mathrm{~W}$. This heat is dissipated through a copper braid and a water-cooling circuit at $294 \mathrm{~K}$. Initial tests at a ring current of $300 \mathrm{~mA}$ have demonstrated proper cooling of the mirror.

The shadow of the cold finger excludes the central energy towards M1 (Table 1). A second mirror, M2, redirects the beam in the horizontal plane and refocuses it in order to reduce its beam size to $26 \mathrm{~mm}$ (horizontal) $\times 19 \mathrm{~mm}$ (vertical), which is necessary for it to pass through the wall of the storage ring at $14 \mathrm{~m}$ from the source.

\subsection{Consideration of possible contamination of the first mirrors}

Carbon deposition and contamination of the first mirror system has become a major concern at third-generation synchrotron radiation facilities. This pollution arises from photochemical reactions of the background gases with the beam. The main gases emitted while irradiating an ultrahighvacuum chamber with a white beam are $\mathrm{H}_{2}, \mathrm{CH}_{4}, \mathrm{CO}$ and $\mathrm{CO}_{2}$ (Kobari \& Halama, 1987). These species could adsorb on the first mirrors M1 and M2, inducing a carbon deposit that would impair reflectivity over time. However, desorption does decrease with dose because of beam cleaning. If the molecular hydrogen contribution remains globally constant with dose, the carbon-containing species do decrease. According to literature data, the desorption level $\eta$ ranges from $8 \times 10^{-5}$ molecules photon $^{-1}$ to $4 \times 10^{-5}$ molecule photon ${ }^{-1}$ for $\mathrm{H}_{2}$ and from $1 \times 10^{-5}$ molecule photon ${ }^{-1}$ to $8 \times 10^{-7}$ molecule photon $^{-1}$ for $\mathrm{CH}_{4}$ after a photon dose of $1 \times 10^{21}$ photon $\mathrm{m}^{-1}$ (Anashin et al., 2004).

Numerous studies have been carried out to elucidate the mechanisms of neutral photodesorption from an illuminated surface (Kobari \& Halama, 1987; Gröbner et al., 1989; Kobayashi et al., 1987; Hori et al., 1993; Andritshky et al., 1988). Two phenomena have been proposed: either direct photon desorption or electron-induced desorption, those electrons being emitted by irradiated surfaces. Even if these two phenomena are difficult to distinguish, some evidence is in carbon deposition on the first optics, it was decided to use specific materials (glidcop) and to set the tooth-like cold finger front-edge facing the beam at a $25^{\circ}$ angle. Additionally, a special motorized shutter acting as a screen just before M1 (used during the degassing stage of the cold finger) has been introduced to allow a soft conditioning of the first mirrors. Three large-size diaphragms have been placed upstream of this shutter to prevent scattered light from the cold finger entering the chamber.

\subsection{Beam propagation and diagnosis}

2.4.1. Ultrahigh vacuum. The beamline is maintained under ultrahigh vacuum (UHV) between a few $10^{-10}$ and $1 \times$ $10^{-9}$ mbar. All the mechanical elements have been chosen for UHV compatibility. Each end-station connection to the UHV is treated differently: (i) microscopy through a Suprasil viewport, (ii) SRCD through a $\mathrm{CaF}_{2}$ viewport and (iii) APEX, windowless, through a differential pumping stage. Indeed, the microscopy line uses photons from $1000 \mathrm{~nm}$ up to the Suprasil cut-off at $180 \mathrm{~nm}$, since in this wavelength range atmospheric gases do not absorb and the line is therefore maintained under static primary vacuum for cleanness only. The wavelength range used for SRCD experiments goes down to $130 \mathrm{~nm}$. A calcium fluoride window isolates the branch line from the experimental chamber flushed with nitrogen. The situation is different for the APEX branch line, for which VUV photons down to $60 \mathrm{~nm}$ are used. Since there is no material transparent below the LiF cut-off around $105 \mathrm{~nm}$, the branch line is fitted with a differential pumping between the exit slit of the monochromator and the experimental chamber in order to work windowless from the atmosphere on the experimental side. Moreover, since atmospheric gases absorb VUV radiation in this domain, the differential pumping unit works at $1 \mathrm{~atm}$ for rare gases (argon or neon) depending on the shorter wavelength to be reached. Interestingly, this differential pumping stage acts as a gas filter preventing higher-order radiation from reaching the experimental areas (Mercier et al., 2000). 
2.4.2. Diagnosis. Owing to the relatively complex optical scheme of the beamline, several focal points are found along the beam path (Fig. 1). All the diagnostic chambers are UHV compatible and pumped by ion pumps (StarCell 50, Varian).

The first focal horizontal point appears at $8 \mathrm{~m}$ downstream of M2. A diagnostic chamber has been installed at this position inside the synchrotron tunnel. It contains a macor target mounted on a lateral motorized translator, which can be inserted to intercept the beam at $90^{\circ}$. The target itself is oriented at $45^{\circ}$ with respect to the beam and faces a camera (SCA640-70gm, Basler Vision Technologies) through a viewport. Therefore, this diagnostic provides an image of the beam and allows for proper tuning of the normal rotation of the M2 mirror.

The first vertical focal point is found $1.67 \mathrm{~m}$ downstream of the mirror M4. At this position the beam size is $56 \mathrm{~mm}$ horizontally $(\mathrm{H}) \times 1.2 \mathrm{~mm}$ vertically $(\mathrm{V})$. For cluttering reasons, the diagnostic chamber has been placed $170 \mathrm{~mm}$ downstream of the focal point. The diagnostic system is composed of three elements: a gold grid, a position-sensitive photodiode (PSD) and a mirror. All of these elements may be inserted and retracted from the beam path.

The gold grid (Precision Eforming, NY, USA) of 70 wires per inch, giving $90 \%$ transmission, is used for photon flux measurements upstream of the partial beam withdrawal for the imaging branch.

A plane mirror made of aluminium-coated silica (Optique $\mathrm{J}$. Fichou et Tofico, France) of $90 \mathrm{~mm}(\mathrm{H}) \times 30 \mathrm{~mm}(\mathrm{~V})$ may be inserted to deflect the beam at $90^{\circ}$ through a $\mathrm{CaF}_{2}$ viewport to a Basler camera. Interferometric filters mounted on the camera allow measurements of the beam shape at different wavelengths in the visible region, as well as fine-tuning of the M3-M4 couple of mirrors.

The PSD measures the position of the photon beam with respect to the theoretical predictions. Because of the large beam size in the horizontal direction, it was not possible to find a commercial PSD allowing measurements in that direction. Hence, we have limited the diagnosis to the vertical direction using a one-dimensional PSD (S3931, Hamamatsu, Japan). A 2.5 optical density filter limits the incident power on the diode.

The second horizontal focal point is found downstream of the M51-M52 mirror system, and $6.8 \mathrm{~m}$ from M4. The beam is
$5 \mathrm{~mm} \times 20 \mathrm{~mm}(\mathrm{H} \times \mathrm{V})$ in size at this position. The diagnostic chamber is placed $500 \mathrm{~mm}$ downstream of the focal point and contains the same set of elements as previously, namely a gold grid, a PSD and a mirror. At this particular position the beam size allows us to use a four-quadrants position-sensing photodiode (SXUV600M, International Radiation Detectors, CA, USA). This detector has been aligned precisely to the theoretical position of the beam. Thus, the detector measures the beam position on both the vertical and horizontal axes. A 2.5 optical density filter also protects the photodiode from excessive thermal loading.

Measurements on the gold grid are compared with those made upstream of the M51-M52 couple to monitor the loss of flux owing to the uptake of the M51 mirror for the imaging line.

The mirror and the imaging system are of the same type as previously, and provide the opportunity to check the shape of the beam at this vertical focal point.

A horizontal focal point is found on the imaging branch line, located $4.96 \mathrm{~m}$ downstream of the M52 mirror. A diagnostic system was placed at this position. It is composed of a macor target oriented at $45^{\circ}$ from the beam direction, which faces a Basler camera. The centre of the target is spotted and aligned to the theoretical position of the beam. Therefore, this element permits a precise positioning of the beam. This point is especially important because the next optical elements on this branch line are located $23.8 \mathrm{~m}$ downstream of M52 (Table 1).

2.4.3. Stability and alignment. The symmetry of the beam is given by the geometry of the cooled diaphragm, centred on the cold finger. The set constituting the cold finger and the diaphragm was conceived in order to conserve the symmetry during dilatation of the parts under heat deposition by the beam.

The M1-M2 mirror system is placed on an independent mechanical module situated inside the vacuum chamber. This module is mechanically decoupled from the chamber and was positioned on an independent base. The stabilities of the optical module were obtained by binding up efficiently the base pole of the mirrors with the storage-ring floor and by locking all degrees of freedom after adjustments (Fig. 4). The aim was to obtain the highest normal mode of the mirrors' structure, using the high stability of the storage-ring floor and

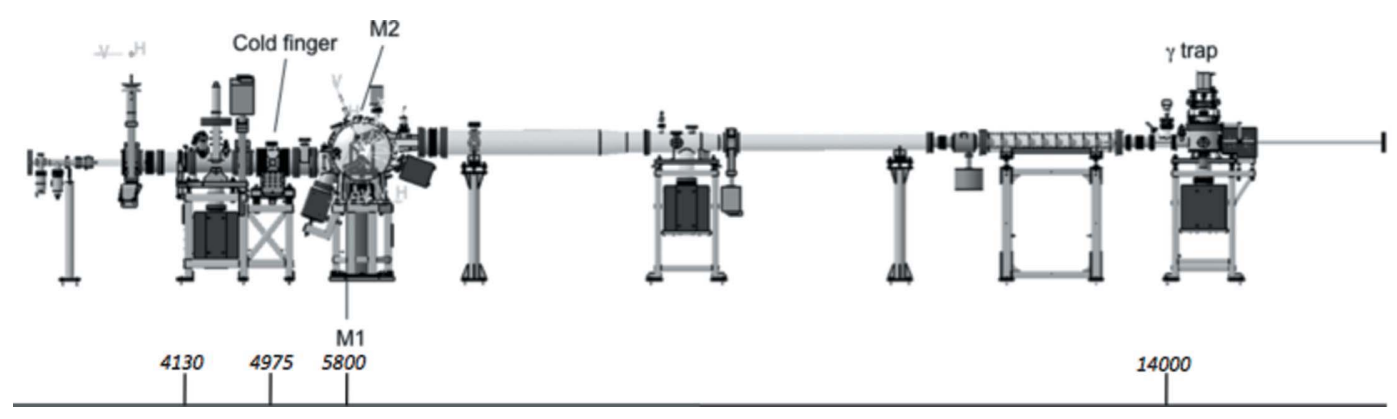

Figure 4

Layout of the DISCO beamline front-end at SOLEIL. Distances from the source point are indicated in mm for some elements. 
the rigid mountings to prevent the propagation or amplification of vibrations coming from the floor or through the vacuum tubes.

The mechanical module with mounted mirrors was prealigned and the optical axes were referenced to external references by relative position measurement, allowing absolute positioning under vacuum. The positions of the mirrors can be directly measured optically. M2 rotation is accessible under vacuum and under beam.

\section{Optical design}

\subsection{General comments}

The general optical layout (Fig. 1) has to comply with the energy, polarization and photon flux requirements of the three end-stations as well as with the congestion occurring from the positions of the end-stations themselves (Fig. 2). In order to solve this problem, the DISCO beamline has been designed as a long and narrow beamline implying very large optics.

\subsection{Choice of materials}

Considering its reflectivity properties over the full energy range of DISCO (1.1-20 eV) (Pallick), silicon was selected as the main material for the optics common to the three branches (Table 1). However, the optics used specifically on the two low-energy branches were coated with particular materials for optimal reflectivity in the wavelength of interest and for polarization conservation issues, namely ruthenium for M6A and GA, and $\mathrm{AlMgF}_{2}$ for M52, M53 and M54.

\subsection{Choice of deviation angles}

Deviation angles of the mirrors and gratings were chosen to maximize the photon fluxes and to preserve the natural polarization of the synchrotron radiation beam. The first four silicon mirrors are at $22.5^{\circ}$ grazing incidence. The vertical pair of mirrors (M1-M2) is followed by another pair of mirrors (M3-M4), which diverts the beam $200 \mathrm{~mm}$ horizontally with the same deviation angle (Fig. 1). Hence, transport and translation of the beam from the storage ring through the radiation protection hutch allows preservation of the polarization as well as compliance with the radiation safety rules of SOLEIL. The safety rules require the translation of the synchrotron radiation out of the cone of the Bremsstrahlung.

Wavelength selection for the SRCD and APEX endstations is provided by a monochromator containing two separate gratings at different incidence angles (Cinel Company, Italy).

The SRCD branch uses a near normal incidence grating (15 ${ }^{\circ}$ incidence angle) to maintain the polarization of the source, whereas APEX uses a grazing-incidence grating $\left(75^{\circ}\right.$ incidence angle) to cover the spectral range up to $20 \mathrm{eV}$. Both gratings and associated focusing mirrors are controlled by the same mechanism.

\subsection{Ray tracing}

The parameters of the optics are the result of numerous optimization iterations with the SOLEMIO software (Table 1). This in-house software combines ray-tracing calculations with optimization iterations. One chooses any parameters, e.g. radius of curvature, distance etc., and sets the minimization criteria, e.g. minimization of the vertical image size (horizontal, or a combination of both) at any point of the beamline, or the maximization of the resolving power over a specified spectral range (in this case it is the average of the spectral width on several wavelengths which is minimized).

For the two mirrors M1 and M2, with the combination of the convex radius of $\mathrm{M} 1$ and the tangential radius of $\mathrm{M} 2$, it is possible to eliminate the curvature of the image (commonly called 'the smile') usually obtained with a single toroidal mirror, to minimize the vertical size of the intermediate image, and to maximize the resolving power. SOLEMIO optimizes simultaneously these two radii of curvature to have the best resolving power for all the spectral range, and then the resulting ray-tracing shows no more curvature at the intermediate image. In the same way, the varied line spacing of the gratings (actually, directly the holographic recording parameters) and the tangential radius of M6 were simultaneously optimized. The varied line spacing is necessary, mostly on the APEX branch, to minimize the defocusing at the exit slit for all the spectral range as well as to maximize the resolving power. The calculated resolving power is between 800 and 3000 for the two branches.

On the SRCD branch the beam diverges vertically by $\sim 5 \mathrm{mrad}$ full width at half-maximum (FWHM) from the exit slit of the monochromator, and it is horizontally focused at $0.5 \mathrm{~m}$ (by the sagittal radius of M6A). At this experimental point the size of the beam is $1.8 \mathrm{~mm}(\mathrm{H}) \times 2.5 \mathrm{~mm}(\mathrm{~V})$ FWHM.

On the APEX branch the beam diverges vertically by 2 mrad FWHM from the exit slit of the monochromator and it is horizontally focused at $1.09 \mathrm{~m}$ on the last slit of the differential pumping (optimization of the shape of the elliptical mirror M3 and of the curvature of M7). At this point the beam is approximately $1.1 \mathrm{~mm}(\mathrm{H}) \times 2.5 \mathrm{~mm}(\mathrm{~V}) \mathrm{FWHM}$.

On the imaging branch the beam is focused vertically and horizontally onto the entrance slit of the monochromator (iHR 320, Jobin Yvon, France), and its numerical aperture at this point fits with the monochromator. The curvatures of the four mirrors M51, M52, M53, M54 are optimized for this purpose, with the constraint of having a narrow beam on M53 and M54, which are very far from M51/M52 (about $24 \mathrm{~m}$ ).

The shape of the elliptical mirror M3 was optimized to have the minimum horizontal size on the last slit of the APEX branch.

The bending magnet provides a degree of circular polarization of about 0.74 at $3 \mathrm{mrad}$ from the central axis, and 0.91 at $5 \mathrm{mrad}$ (our maximum acceptance). This distribution is propagated to the circular dichroism branch experimental point, with an angular vertical magnification of about 0.85 , and only a very little decrease of the degree of polarization (about 
-0.01), because, from a polarization point of view, M3/M4 compensates M1/ M2, and M6A and GA are near normal incidence.

\section{Beamline commissioning}

\subsection{Beam shape and size}

From the bending magnet, $2.3^{\circ}$ are extracted at $1.7^{\circ}$ of the zero tangent. The beam then passes through a crotch absorber at $1.5 \mathrm{~m}$ from the source, which defines its dimensions. At $4.13 \mathrm{~m}$ a trapezoidal diaphragm reshapes the beam and represents the optical aperture with maximum tolerances accommodating beam position shifts while maintaining a constant beam shape (dimensions: length $165.8 \mathrm{~mm}$; inner and outer height of the trapeze shape with respect to the storage ring: 45.1 and $38.2 \mathrm{~mm}$, respectively).

The beam shape close to the first vertical focal point, theoretically calculated by wave propagation calculations using SRW (Chubar \& Elleaume, 1998), appears to be well balanced between the upper and lower part (Fig. 5). Measurements are in accordance with prediction (Fig. 5).

The $S R W$ software predicts the spectral, spatial and polarization properties of the radiation in the near-field and/or farfield approximation produced by a relativistic electron beam travelling through the corresponding bending-magnet field of $1.71 \mathrm{~T}$. The computed wavefront of the radiation can be propagated through drift spaces, lenses (mirror, refractive, Fresnel etc.), apertures or arbitrary two-dimensional phaseshifting elements.

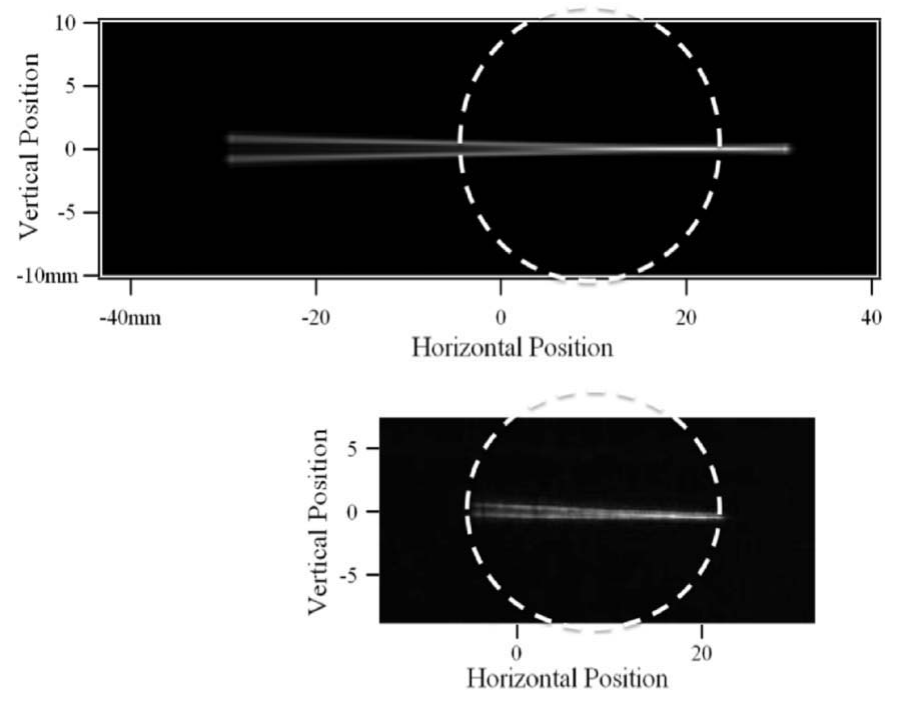

Figure 5

Photon projection recorded (bottom) $0.32 \mathrm{~m}$ before the first vertical waist, and simulation with $S R W$ (top) of beam shape on the same virtual object plane. Light is filtered using a $633 \mathrm{~nm}$ bandpass filter. The dotted circle identifies the region captured by the camera (camera field of view).
In combination with the SOLEMIO calculations, these predictions have proven to be very useful in assessing the beam shape at the horizontal focal points.

Initial images at the first horizontal focal point diagnostic, $14 \mathrm{~m}$ from the source (Fig. 6), identified a negative tilt of $0.1^{\circ}$ of mirror M1 (axis $R_{n}$ ) responsible for the tilted shape of the fan of the focused beam, compared with predictions. These first images, recorded at low storage-ring current of $2 \mathrm{~mA}$, also show an equal proportion of the top and bottom parts of the beam, thereby indicating a very good central alignment of the cold finger (Fig. 6).

At the following vertical horizontal point, $18.5 \mathrm{~m}$ from the source, at the exit of the radiation protection hutch a provisional $\mathrm{CCD}$ camera with focusing lenses was mounted.

The shape of the horizontal focal point (Fig. 6), taken without objective, demonstrates very well the accordance between measurement and prediction. The difference in height is due to the underestimation of low-intensity regions by the camera.

\section{Summary}

In this article we have presented the design and the characteristics of the first extracted beam of the DISCO beamline at the SOLEIL synchrotron radiation facility. Front-end energy selection and optical design have been optimized for the three end-stations. Special attention was given to the protection against pollution of the first mirrors and dedicated diagnostics. Ray-tracing calculations using the SOLEMIO inhouse software allowed optimization of the optical parameters. The first experimental measurements of the beam shape and size were in excellent agreement with the wave propagation using $S R W$ and SOLEMIO calculations. The agreements found at various positions along the beam path confirm an excellent alignment of the front-end optical components. The three end-stations of the beamline will be operational in September 2009. 
We would like to thank S. V. Hoffman from ISA for fruitful discussions. C. de Oliviera and D. Lefebvre contributed greatly to the beamline installation. J. C. Maurizot initiated this work in 2002.

\section{References}

Anashin, V., Collins, I. R., Dostovalov, R. V., Fedorov, N. V., Krasnov, O. B., Malyshev, O. B. \& Ruzinov, V. L. (2004). Vacuum, 75, 155159.

Andritshky, M., Gröbne, O., Mathewson, A. G., Schumann, F., Strubin, P. \& Souchet, R. (1988). Vacuum, 38, 933-936.

Chubar, O. \& Elleaume, P. (1998). Proceedings of the Sixth European Particle Accelerator Conference (EPAC98), Stockholm, Sweden, 22-26 June 1998, pp. 1177-1179.

Clarke, D. T. \& Jones, G. (2004). J. Synchrotron Rad. 11, 142-149.

Dumas, P., Polack, F., Lagarde, B., Chubar, O., Giorgetta, J. L. \& Lefrançois, S. (2006). Infrared Phys. Technol. 49, 152-160.

Gekko, K., Ojima, N., Sakai, K., Matsuo, K., Matsui, T., Fukazawa, T., Namatame, H. \& Taniguchi, M. (2001). Chem. Lett. 6, 522-523.

Gröbner, O., Mathewson, A. G., Strubin, P., Alge, E. \& Souchet, R. (1989). J. Vac. Sci. Technol. A, 7, 223-229.
Hoffmann, A., Kane, A., Nettels, D., Hertzog, D. E., Baumgärtel, P., Legenfeld, J., Reichardt, G., Horsley, D. A., Seckler, R., Bakajin, O. \& Schuler, B. (2007). Proc. Natl. Acad. Sci. 104, 105-110.

Hori, Y., Kobayashi, M., Matsumoto, M. \& Kobari, T. (1993). Vacuum, 44, 531-553.

Kobari, T. \& Halama, H. J. (1987). J. Vac. Sci. Technol. A, 5, $2355-$ 2358.

Kobari, C., Matsumoto, M., Ikeguchi, T., Ueda, S., Kobayashi, M. \& Hori, Y. (1990). AIP Conf. Proc. 236, 347-354.

Kobayashi, M., Matsumoto, M. \& Ueda, S. (1987). J. Vac. Sci. Technol. A, 5, 2417-2420.

Matsuo, K., Yonehara, R. \& Gekko, K. (2005). J. Biochem. 138, 79 88.

Mercier, B., Compin, M., Prevost, C., Bellec, G., Thissen, R., Dutuit, O. \& Nahon, L. (2000). J. Vac. Sci. Technol. A, 18, 2533 2541.

Miron, S., Réfregiers, M., Gilles, A.-M. \& Maurizot, J.-C. (2005). Biochem. Biophys. Acta, 1724, 425-431.

Sutherland, J. C., Desmond, E. J. \& Takacs, P. Z. (1980). Nucl. Instrum. Methods, 172, 195-199.

Tao, Y., Huang, Y., Qian, H. J., Yan, Y. N., Xu, J. H., Zheng, H. W., Sheng, Y., Li, X. W. \& Li, D. M. (2001). High Energy Phys. NuC. 25, 66-69.

Troxell, J. D. (1989). IEEE Symp. Fusion Eng. 2, 761-765. 